\title{
Legal Professions as the Reporting Parties in Anti-Money Laundering Regime: How Can Professions Actively Contribute?
}

\author{
Go Lisanawati ${ }^{1}$, Njoto Benarkah ${ }^{2}$ and Yoan Nursari Simanjuntak ${ }^{3}$ \\ ${ }^{1}$ Faculty of Law, University of Surabaya, Raya Kalirungkut, Surabaya, Indonesia \\ ${ }^{2}$ Faculty of Engineering, University of Surabaya, Raya Kalirungkut, Surabaya, Indonesia \\ ${ }^{3}$ Faculty of Law, University of Surabaya, Raya Kalirungkut, Surabaya, Indonesia
}

\begin{abstract}
As it is believed by the International and national society, the active participation of professions (including legal professions) is urgent and significant in anti-money laundering prevention. The International society has been put professions as reporting party since it has been identified as gatekeeper through their profession. One of the important construction has been developed in order to bridging the problems that appears in the dicussion of this role. The debatable discussion related with the code of conduct of the professions versus the of anti-money laundering mandate as the reporting party's responsibility. Actually, the problem is also related with the content of the reports. Some sources as mentioned in the Law of Anti Money Laundering, Government Regulation and Head of INTRAC 's regulation shall be elaborated. As it is designed in the law and regulations on anti-money laundering, it should be active participation of the legal professions and other professions as mentioned in the Government Regulation Number 43 of 2015. To comply with this requirement, it needs self-awareness of the legal professions to do reporting once they meet the requirements.
\end{abstract}

\section{Introduction}

Money laundering is a never ending crime. Further discussion and prevention methods have been conducted, that does not mean the perpetrators stop using it as a tool to gain their own benefit from any illegal activities. It does not mean also that the method become less. The methods have been develop from time to time and now become sophisticated, and involving not only layman, but also white collar. Money laundering in its characteristic will play into an important part of perfect crime in hide and conceal the source of the crime itself.

The Financial Action Task Force has been identified the vulnerabilities of legal professions and other professions and put them as reporting parties. FATF RBA Guidance of Legal Professions (p.5) explains that:

\footnotetext{
* Corresponding author: go_lisanawati@staff.ubaya.ac.id
} 
Legal professionals provide a range of services and activities that differ vastly, such as in their methods of delivery and in the depth and duration of the relationships formed with clients. (Laundering \& Typologies, 2008).

The white collar (in the meaning of legal professionals and other professions) can be understood has been developing into a vehicle as method of delivery, and other things. Client in the perspectives of consumer protection always becomes a special person to be protected under the name of professionals' ethics and code of ethics. Thus, it needs to raise the awareness of the purposed professions through self-awareness that included their professionals' ethics. In relate with this fact, AUSTRAC (Australian Financial Transaction Report, p.4) through their report mentions that:

The use of legal practitioners to launder illicit funds is an internationally established money laundering method. In Australia, the increasing complexity and sophistication of money laundering schemes has seen organized crime groups seek specialist advice and skills of professionals, such as legal practitioners. Professionals are known as 'gatekeepers' or facilitators (Strategic analysis brief, 2015). The keyword here is gatekeeper. In this sense, it might understood that organised crime perpetrator such as money launderer will find many ways to keep their illegal gain safely and away from the complicated inspections. As a part of organised crime, money laundering will dealing with the sophisticated process. The perpetrator will not only commit solely. Organised crime usually abuse many things such as anything regarding with the "secrecy". Legal professionals can act as main protector to hide the illicit funds away from the financial system through a misuse and misconduct the professionals. Legal professionals can put as the main entry point to do structuring illicit money. Legal professionals can give provide advice and mostly because the common perspective that the ethics will play. In relation with this fact, Chat Le Nguyen (p.54), as quote from Chambos, strengthens that:

Hence, these people often seek the skilled banking systems that provide strict banking secrecy. In response to the customer's demand for financial secrecy, divergent national and international bankers have offered banking secrecy as a kind of product. They compete with one another in terms of quality or cost of this type of product. Further, desirable banking systems are usually located in countries renowned for their political, social, economic and monetary stability known as "banking secrecy havens"(Le Nguyen, 2018). In other word, the secrecy is becoming the first keyword to seek protection. Secrecy and ethics will be a crucial vehicle to facilitating their illegal activities. Legal professions are the enabling party to actively do the money laundering.

Further, Chambos as quoted by Chat Le Nguyen strengthens that there is an odd perspectives that shall be change. As mentioned by the Financial Action Tasks Force, professional vehicle as "the protector" is used. Some clients believes that the professionals will tied with the ethics of conduct only for client without doubt, while the law has required professionals to disclosed some information related with some issues of the "money laundering abuse" committing by the offender, and shall conduct customer due diligence in knowing their client as customer. In this condition, it needed a certain action from the people who targetted by the offender to be "place" or "heaven". Those people called then as "Reporting Parties". The effectiveness of reporting party in the reporting scheme for anti money laundering regime is important to be constructed. 


\section{Discussion}

\subsection{Reporting Obligation and Legal Professionals as Reporting Party in Anti- Money Laundering Scheme}

As explained above, money laundering has manifestated into a serious and complex tools or vehicles choosen by the offender of predicate crimes to get illicit gain without detection. Otherwise, the money seems legitimate until it recognized and considered as illegal. In this context, money laundering scheme is more difficult than the predicate crime itself. The purposes of conduct money laundering is actually to hide the nature of the money that is actually coming from illicit sources. Money laundering will assist the conversion on the sources of funds or money or assets. Money laundering is actually can be distinghuised into 3 (theree) models, such as:

- Money laundering that is actively conducted by the offender of predicate crimes. In the context of active money laundering, the offender will be active in finding the path to hide the money. In this construction, it is quite difficult to ask perpetrator to comply with the obligation to disclose the information correctly and actively. The possibility to avoid abuse action by the offender will only achived if the other parties that may involved in that money laundering circle is aware that they may be a potential victim of that perpetrator.

Active money laundering can be described as below:

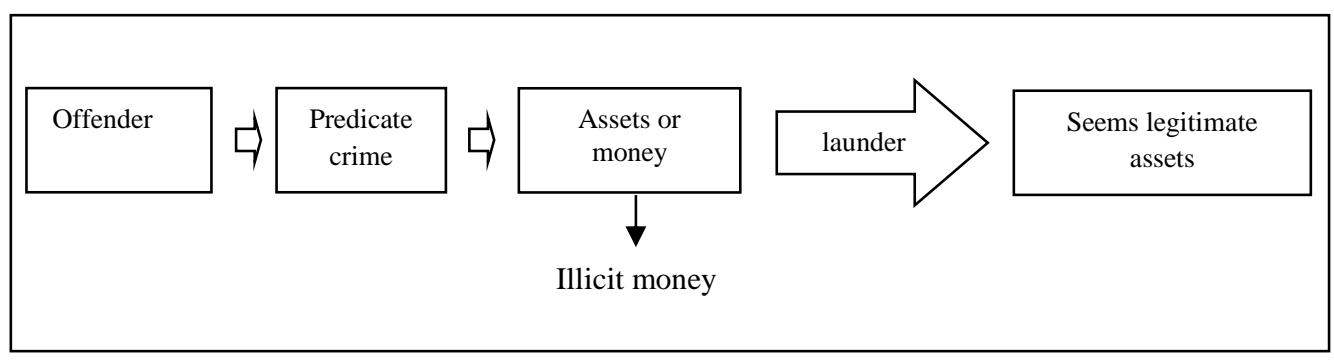

Fig. 1. Scheme of Active Money Laundering conducting by the Offender of Predicate Crime

- Indirect active money laundering through a active facilitator. The money laundering offender here is not the predicate crimes offender. There is another party categorized as facilitator in conducting active money laundering. The use of facilitator could be choosen by the predicate crime offender to make a perfect crime. Without any assistance from the facilitator, it could not be smooth to gain the assets. The risks shall be borne by the facilitator, since they know that the purpose of the predicate crime offender is to hide the illegal money derived from crime.

Legal professions can be played here if they did not recognized since the beginning and comply with the obligations. More over, some clients and legal professionals are believe that there is ethics which shall be adamantly kept. In this matter, the professionals shall aware the potential risks which may arise since ethics does not mean only to protect client but also the country and themselves. FATF included the professionals as Professional Money Laundering. Further FATF mentions that Professionals Money Laundering (PMLs) can belong to 3 (three) categorized called as Individual PML; Professionals Money Laundering Organisations; and 
Professionals money laundering network. Each of those PML explained by FATF (pp. 12-13) as below:

An individual PML is anyone who possesses specialised skills or expertise in placing, moving and laundering funds. They specialise in the provision of ML services, which can also be performed while acting in a legitimate, professional occupation. These services can include, but are not limited to, the following: accounting services, financial or legal advice, and the formation of companies and legal arrangements (see specialised services, below). Individual PMLs often spread their risks across diverse products, and carry out business activities with several financial specialists and brokers.

A Professional money laundering organisation (PMLO), which consists of two or more individuals acting as an autonomous, structured group that specialises in providing services or advice to launder money for criminals or other OCGs. Laundering funds may be the core activity of the organisation, but not necessarily the only activity. Most PMLOs have a strict hierarchical structure, with each member acting as a specialised professional that is responsible for particular elements of the ML cycle.

A Professional money laundering network (PMLN), which is a collection of associates or contacts working together to facilitate PML schemes and/or subcontract their services for specific tasks. These networks usually operate globally, and can include two or more PMLOs that work together. They may also operate as informal networks of individuals that provide the criminal client with a range of ML services. These interpersonal relationships are not always organised, and are often flexible in nature.(Professional Money Laundering, 2018)

Regarding with that, a facilitator can work as individual, organization, or even a network. This condition is important to be understand. It is like a spiderweb. A professional money laundering who working as individual will continue to work in an interaction in the form of organization, and more over it will build a network. Thus, it makes the processes will more difficult to be analyzed since it has become more organized.

The Indirect active money laundering thorugh a facilitator can be constructed as below:

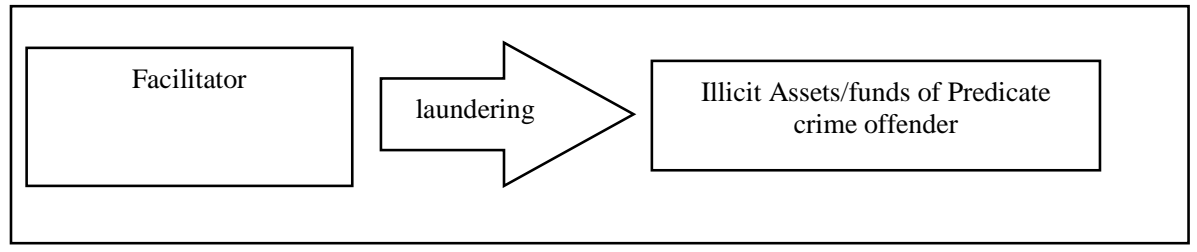

Fig. 2 Scheme of Indirect Active Money Laundering conducting by facilitator

- Passive money laundering. In this construction, the laundering will not conducted by the offender of predicate crimes or using other people to hide and to convert the illicit money. The passive money launderer here is only receive a placement or transferring of an illicit funds of the predicate crimes offender. In this scheme, the passive money launderer may not have the same intention with the predicate crimes offender. The process will be different if it is comparing with the condition of the construction of facilitator. But for a protection, these kinds of people who receive any placement or transferring of the illicit funds shall understand that anything that they received without a knowledge to know where the money comes from will lead them to be the passive money laundering. In this scheme, the position of passive money laundering 
is not the think tank of the money laundering processes. They must conduct identifications tools including client due diligence, and deep identification, to know the risks which may burdened to them.

The contruction of the Passive Money laundering can be describe as below:

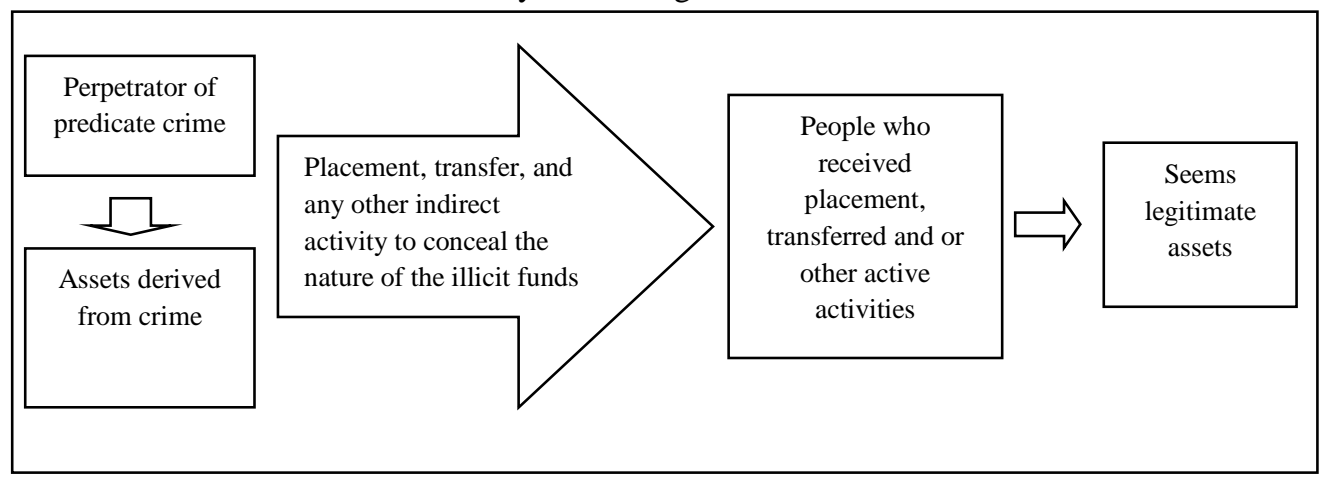

Fig. 3. Scheme of Passive Money Laundering

Money laundering process will not only effected to the economic life of a nation, but also the entire people. Middleton and Levi also mention the needed to shift the narrow perspectives how money laundering can happen. Further, Middleton and Levi explains as below:

It is broadly accepted that explanations of crime that focus solely on the motivations of 'primary offenders' are too narrow. In academic, policy and practitioner circles, there is increasing interest in the hinterland of crime commission, which now goes under the generic name of organized crime 'enablers' ... This includes lawyers as crime facilitators on a spectrum from active conspirators through wilfully blind to unwitting actors... (Middleton $\&$ Levi, 2015). Further, in their explanation, Middleton and Levi addressed the idea of "crime enabler" approach. They categorized it as a model of organized crime. In other word, it can develop the role into a mechanism of conducting crime. Legal professionals can act to commit the predicate crime for themselves, and become a facilitator for crime comitted by others. The reason begin under the name of Legal professional privilige and professionals' ethics.

It can be reviewed that the risk is not coming when the professionals committed the crime of money laundering because conducting predicate crimes, but the awareness concerning the potential risks to be used as a gatekeeper. It will put them as the facilitator of money laundering crime. Thus, it can be understood as an ethical misconduct. It can be distinguished how ethic can participate as a tool to a self-reminder for not involve in their professions. Once again, Ping He (p. 4) reminds that: "The fact that lawyers, notaries, accountants and other independent professionals are vulnerable to money laundering activities is really linked with the nature of their professions. That is to say, the nature of these professions indicates that some of these professionals will invariably be utilized by money launderers." (He, 2006). Indonesia, as a country that consistent to implement anti money laundering regime has also regulating the active participation of the professionals to protect them from the possibility of being vehicles of the clients. The law has already given legal protection to the professionals to active in giving reporting. It means that the law has guarantee the prevention ways to give active reporting regarding with some important detection points. 


\subsection{Active Reporting Construction through Self-Awareness of the Legal Professionals}

As explained above, legal professionals are in high risks when they only think from the narrow perspectives that money laundering will only happen when they commit the money laundering actively as a person who conducted predicate crime. The risk is also come through their ethical and disciplines. Since the development of money laundering has already touch the code of conduct and professionals' ethics, the law shall touch the sense of self awareness of the reporting parties, including the legal professionals. Ping He (p. 64) then mentioned: Lawyers, notaries, accountants and other professionals are vulnerable to money laundering activities on one hand; on the other hand, if these professionals undertake anti-money laundering obligations, they will exert a more distinct effect than financial institutions... three main duties concerning customer identification, record keeping and reporting of suspicious transactions are imposed on financial institutions under many international documents and national regulations. But these three duties are insufficient, especially at present, when money-laundering schemes are getting increasingly complicated. (He, 2006)

As mentioned in the Law Number 8 of 2010 concerning Prevention and Eradication of Money laundering and the Government Regulation Number 43 of 2015, there is reporting obligation that should be fulfilled by the legal professionals. It has been appointed in the Article 3 of the Government Regulation Number 43 of 2015 inter alia with the Article 17 (2) of the Law Number 8 of 2010. In the reporting obligation, the legal professionals shall understand the points of reporting. Legal professionals shall understand their client or candidate clients.

There are 3 (three) indicators that should be reported by the legal professionals as reporting parties.

1. The client transactions are indicated as suspicious transactions. According to the Article 1 number 5 of the Law Number 8 of 2010 inter alia with the Article 1 number 8 of the Government Regulation Number 43 of 2015, explains that the indicators of suspicious transactions are:

a. Financial Transaction of which is diverging from its profile, characteristic, transaction pattern habits of the User in question;

b. Financial Transaction of which is made by the User that is reasonably suspected to be made for the purpose of avoiding the report of the Transaction in question of which is mandatory performed by the Reporting Party in accordance with the provision herein;

c. Financial Transaction of which is made or aborted to be made using Assets that are alleged comes from the criminal action; or

d. Financial Transaction of which is required by the PPATK (=INTRAC) to be reported by the Reporting Party due to involve the Assets that are alleged comes from the criminal action.

2. The legal professionals are representing any activities for and on behalf of clients related to Article 8 of the Government Regulations Number 43 of 2015. The activities are:

a. Buying and selling a property; and or

b. Managing money (funds), security, and other financial product; and or

c. Managing cheque accounts, saving accounts, deposit accounts, and securities accounts; and or

d. Operating and managing company;

e. Establishing, buying and selling company

3. Meet with one of the conditions of the client transactions as mention in the Head of

INTRAC Regulation Number 11 of 2016. There are 19 activities that may reported when the client. 
The words Users as mention can be read as Client. As it may understood, those requirements are cumulative. If the client and the information are not meeting with the one of three indicators, professions do not need to do reporting. In relate with that position, the professions shall aware which may cause vulnerability for them. They should conduct a "diagnose" to which activities that the client did.

There are 2 conditions that shall bring a termination to the relationship between legal professionals and clients. The conditions are (inter alia Article 5 subparagraph 1 of the Government Regulation Number 43 of 2015):

1. The clients refused to comply with the Customer Due Diligence, Enhance Due Diligence, and other identification method conducting by the legal professions.

2. The professions are doubted on the information given by the clients.

In this position, self-awareness of legal professions must seek how to know the reporting points, obligations, and other information that might hide by the clients. Ethics of professionals will lead the professionals to away from the criminal prosecution or civil law suits only when they realize that their ethics must be complied with the law. The client cannot suit them as long as any obligations have been conducted with full of attentions and responsible. The main law or professionals' ethics will never put them into a harm condition. It is protected rather than give condemnation to them. Further, the legal professionals shall implementing the part 3 - part 7 (Article 6 - Article 28) regarding with the registration, reporting, report keeping obligations. The entire process should be implemented. The process will bring an independency for the party whether they will report it or not. But the important thing is that the legal protection will only give when the reporting parties (=legal professionals) shows their good willing, and serious attention to be an active reporting parties. In the reporting process, it does not need to do periodically reporting. It is only an occasional reporting when the client meets those three requirements as explained above.

As the result of the research, the researcher has developed a tool to elaborate those requirements and facilitate the legal professionals to be active in a willingness to do reporting. The software is manifested in the website that can be accessed and diagnosed whether they should report or not related with the client or candidate clients. The software will connect to the website of PPATK (=INTRAC) to do the official registration. The website is a tool for legal professions to help them in diagnosing the information given by the clients. This is like e-learning tools for common people to understand money laundering and other important information to know about money laundering. The software has checking tools for professionals and after that will take to the reporting obligations or not.

\section{Conclusion}

As money laundering has appeared and manifested into a very serious and dangerous crime, involving many parties, including those professionals that have been put as Gatekeeper and vehicles to make the illicit money safe. This vulnerability and potential risk that may follow them when they are not aware to build self-awareness and the mind that let the discussion of the contradiction between the ethical obligation and laws on money laundering into a narrow position. It will bring them away from the legal protection given by the laws on money laundering itself. Thus, it is important to know well what is the indicators and point of reporting as mention in the law, and elaborated them into a proper detection and diagnose through developing any tools to get the best result in diagnose. 


\section{References}

1. He, P. Lawyers, notaries, accountants and money laundering. Journal of Money Laundering Control 9, 1, Pp 62 - 70. https://doi.org/10.1108/13685200610645229 (2006).

2. Laundering, M., \& Typologies, T. F.. Financial Action Task Force Groupe d'action financière. https://doi.org/10.1787/9789264018082-en (2008).

3. L. Nguyen, C. Preventing the use of financial institutions for money laundering and the implications for financial privacy. Journal of Money Laundering Control 21, 1, Pp 4758. https://doi.org/10.1108/JMLC-01-2017-0004 (2018).

4. Middleton, D., \& Levi, M. Let Sleeping Lawyers Lie: Organized Crime, Lawyers and the Regulation of Legal Services. British Journal of Criminology, 55, 4, Pp 647-668. https://doi.org/10.1093/bjc/azv001 (2015).

5. Professional Money Laundering. Retrieved from www.fatf-gafi.org, (2018).

6. Strategic analysis brief. Retrieved from http://www.austrac.gov.au/sites/default/files/sabrief-legal-practitioners.pdf (2015). 